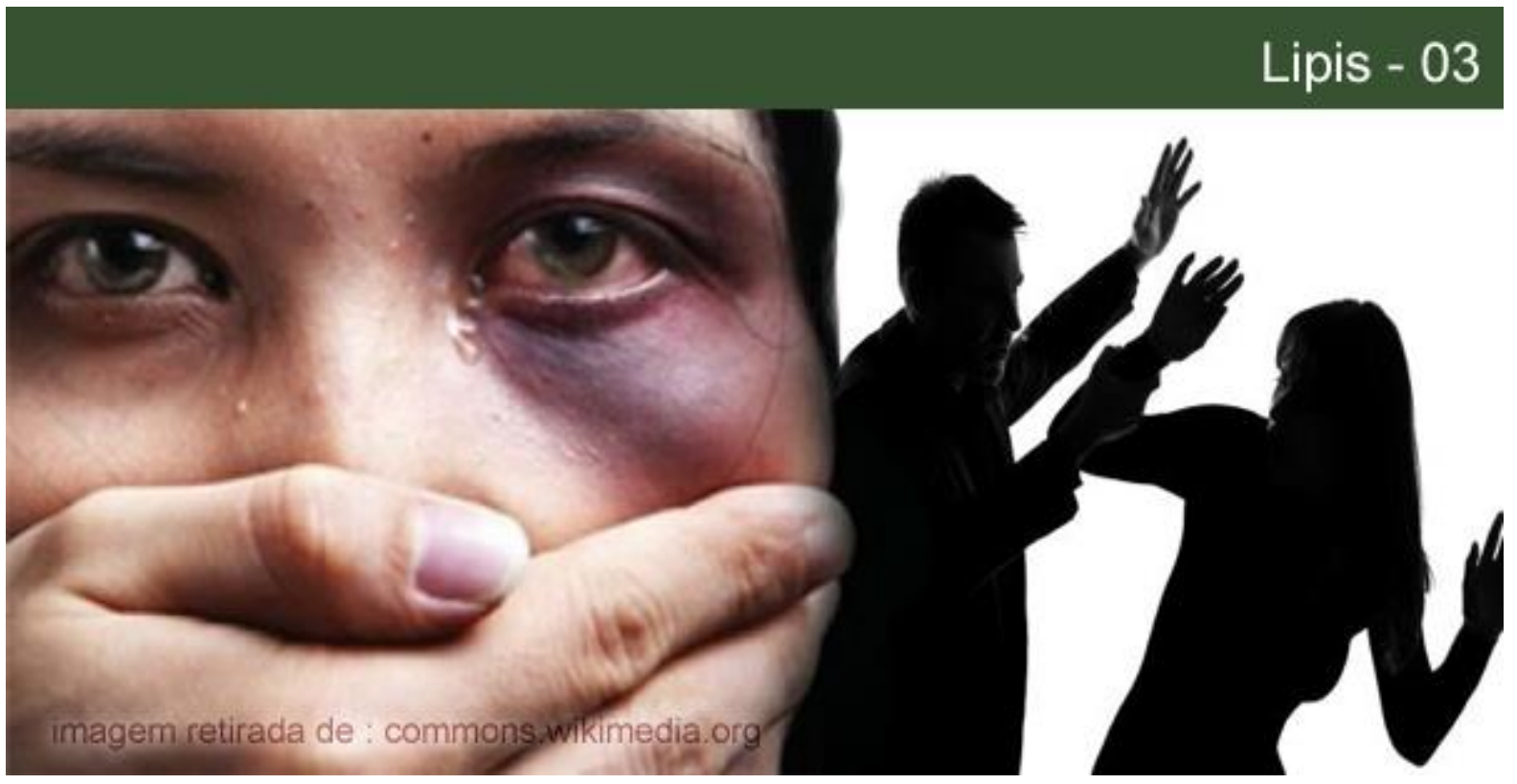

\title{
REVISÃO SISTEMÁTICA NAS BASES DE DADOS PEPSIC E SCIELO ACERCA DA PRODUÇÃO CIENTÍFICA BRASILEIRA SOBRE VIOLÊNCIA CONTRA AS MULHERES NO PERÍODO DE 2013 A 2015
}

\begin{abstract}
Bárbara Araújo Sordi
Psicóloga. Especialista em Psicologia Hospitalar e da Saúde. Mestre e Doutoranda no Programa de PósGraduação da UFPA na linha de Psicanálise: Teoria e Clinica. Participante do Laboratório de Psicanálise e Psicopatologia Fundamental, grupo de pesquisa presente do Diretório de Grupos do CNPQ, desde junho de 2012. Membro pesquisador do projeto de pesquisa "Relações de gênero, feminismos, sexualidade, vulnerabilidade e, a feminização da epidemia do HIV-AIDS" (pesquisa financiada pelo Conselho Nacional de Desenvolvimento Científico e Tecnológico-CNPq). E-mail: barbarasordi@hotmail.com.
\end{abstract}

Resumo: A violência contra as mulheres é um problema mundial e uma realidade brasileira. Atualmente cresce o número de pesquisas sobre a temática. Este artigo busca analisar a produção científica publicada entre 2013 e 2015 nas bases de dados Pepsic e Scielo. Foram incluídas pesquisas disponíveis online e publicadas na íntegra. Utilizaram-se como critério de exclusão os artigos sem padrão científico publicados no exterior ou em língua estrangeira e documentos governamentais. Como resultado foram analisados 65 resumos, qualitativos em grande parte, publicados por até três autores, a maioria mulheres. A violência física foi a principal pesquisada, seguida da violência psicológica. Não se encontrou artigo sobre violência patrimonial, apenas dois sobre feminicídio e 5 sobre violência sexual, porém nenhum abordando sobre a cultura do estupro, tema de atual relevância. Este estudo converge com a tendência atual em pesquisar a violência de forma qualitativa. Almeja-se que contribua com futuras pesquisas e com políticas públicas que deem visibilidade à problemática e alcance as mulheres em suas distintas realidades de violência.

Palavras-chave: Violência contra as mulheres. Violência de gênero. Violência doméstica.

\section{SYSTEMATIC REVIEW OF PEPSIC AND SCIELO'S DATA BASES ABOUT THE BRAZILIAN SCIENTIFIC LITERATURE ON VIOLENCE AGAINST WOMEN FROM 2013 TO 2015}

Abstract: Violence against women is a global problem and a Brazilian reality. The number of researchs on the subject is currently growing. This article seeks to analyze the scientific literature published between 2013 and 2015 in Pepsic and Scielo's databases. Online and published in full available surveys were included. Articles without scientific standard published abroad or in a foreign language and government documents were used as criteria for exclusion. As a result 65 abstracts were analyzed, almost qualitative, published by up to three authors,

\section{POLÊM!CA $\mid$ LABORE (}

Polêmica - Revista Eletrônica da Uerj - Rua São Francisco Xavier, 524, $1^{\circ}$ andar

bloco D, sl.1001 • Tels.: +55 21 2334-4088/4087 • http://www.e-publicacoes.uerj.br/index.php/polemica/index

http://www.labore.uerj.br • laboreuerj@yahoo.com.br 
most women. Physical violence was the main researched, followed by psychological violence. No article on patrimonial violence were found, only 2 of femicide and 5 on sexual violence, but no one covering on the rape culture, the subject of current relevance. This study converges with the current trend in researching violence qualitatively. It aims to contribute to future research and public policies that give visibility to the issue and reach women in their different realities of violence.

Keywords: Violence against women. Gender violence. Domestic violence.

\section{Introdução}

A violência contra as mulheres, apesar de ser um fenômeno antigo, é uma realidade mundial, que por sua gravidade propicia um número crescente de pesquisas e estudos teóricos. Embora a palavra "violência" tenha um significado polissêmico dentro da literatura, sobretudo das Ciências Sociais, o termo "violência contra a mulher" assume um caráter que a circunscreve. Originada no movimento feminista, sua definição consiste em todo e qualquer ato violento baseado no gênero que poderá resultar em dano físico, psicológico, sexual ou de sofrimento para mulher, incluindo ameaças, coerção e/ou privação de liberdade em ambiente público ou privado (BRASIL, 2006; COELHO, 2015; SILVA et al, 2015).

No Brasil, os estudos científicos sobre violência contra as mulheres iniciaram na década de 1980, momento da redemocratização e efervescência dos movimentos sociais, tornando-se - até os dias atuais - um dos principais temas dos estudos feministas no país, tendo como principal objeto das pesquisas a violência conjugal (SANTOS \& IZUMO, 2005).

Muitos autores também nomeiam a violência sofrida por mulheres como violência doméstica (VD) ou violência de gênero (VG) (SILVA \& OLIVEIRA, 2013), contudo há críticas que irão apontar a necessidade de rigor científico dentro dos estudos feministas (SCOTT, 1990), pois é comum encontrar conceitos, tal como os acima, utilizados indiscriminadamente como sinônimos, sem considerar o contexto sociohistórico e a corrente teórica do autor utilizado (SANTOS \& IZUMINO, 2005).

Ainda que a violência contra as mulheres (VCMS) faça parte da história do Brasil, houve um ganho ainda maior de notoriedade há aproximadamente dez anos com a Lei 11.340/2006, que recebe o nome de uma vítima de violência doméstica, sendo, portanto, popularmente conhecida como Lei Maria da Penha. A promulgação desta lei tornou evidente que a violência contra as mulheres é um problema de saúde pública e responsabilidade do Estado, ao considerar a violência doméstica e familiar como violência física, psicológica, patrimonial, sexual e/ou moral, delegando serviços de atendimentos, procedimentos a serem tomados e institucionalizando legalmente a violência como um crime específico, passível de

\section{POLÊM!CA $\mid$ LABORE}


punição conforme a agressão (BRASIL, 2006; AMARANTINO; DEL PRIORI, 2011; CUNHA, 2014).

Em 2015 foi sancionada a Lei 13.104/2015, a Lei do Feminicídio, a qual irá classificar o homicídio de mulheres de forma intencional e violenta, pela condição de sexo, como crime hediondo e com agravantes quando acontecer em situações específicas de vulnerabilidade gravidez, menor de idade, na presença dos filhos, entre outros. Para a Lei, existe feminicídio quando a agressão envolve violência doméstica e familiar ou quando evidencia menosprezo/discriminação à condição de ser mulher (BRASIL, 2015).

Devido à escassez de dados, o Mapa da Violência também publicado em 2015 considerou como feminicídio as agressões cometidas contra uma pessoa do sexo feminino no âmbito familiar da vítima que, de forma intencional, causaram lesões ou agravos à saúde que culminaram em morte (BRASIL, 2015).

Utilizando como base o Sistema de Informações de Mortalidade (SIM) da Secretaria de Vigilância em Saúde (SVS) do Ministério da Saúde (MS), o Mapa de Violência (2015) afirmou os seguintes dados: entre 1980 e 2013, 106.093 mulheres foram vítimas de homicídio pela condição de ser mulher, taxa crescente confirmada nos dados estatísticos, uma vez que o número de vítimas passou de 1.353 em 1980 para 4.762 em 2013, evidenciando um aumento de $252 \%$. Este dado também demonstra que essas 4.762 mortes em 2013 representam 13 homicídios femininos diários. A taxa, que em 1980 era de 2,3 vítimas por 100 mil pessoas, passou para 4,8 em 2013, um aumento de $111,1 \%$.

Estes dados estatísticos confirmam que a condição de ser mulher ainda pode ser considerada como um fator de vulnerabilidade e difere-se da violência interpessoal quanto ao agressor por, na maioria das vezes, ter como característica comum o convívio familiar e ser na maior parte praticada pelo parceiro íntimo no ambiente doméstico (DINIZ et al, 2011).

O medo, a vergonha e a falta de compreensão dos procedimentos legais, além da própria cultura que naturaliza a dominação masculina e a subordinação feminina, são fatores que interferem na procura de ajuda por parte das vítimas, sejam elas jurídicas ou de saúde (SILVA, VALOGUERO \& LUDEMIR, 2012; BRASIL, 2006).

De acordo com Silva e Oliveira (2013), apesar dos numerosos estudos sobre violência contra as mulheres, verificam-se os diferentes métodos e instrumentos de mensuração, fato que dificulta uma leitura uniforme do fenômeno analisado. Além disso, são poucos estudos

\section{POLÊM!CA $\mid$ LABORE}


que se propõem a fazer uma análise dos artigos publicados e de levantamento bibliográfico sobre tais, fato que será evidenciado ao longo desta pesquisa. Utilizando como referencial a pesquisa dos autores supracitados, que realizaram uma revisão sistêmica acerca da produção científica nacional no período entre 2009 e 2013, este artigo tem como objetivo dar continuidade ao estudo e realizar a revisão sistemática nos últimos três anos, contudo, propondo-se a realizar a análise dos resumos publicados em duas fontes científicas de reconhecimento na academia brasileira.

Considera-se esta pesquisa relevante devido à possibilidade de auxiliar novos estudos que se debrucem sobre a temática, proporcionando, por meio da revisão bibliográfica, um panorama das produções existentes para que possam ser avaliadas e a veiculação de informações importantes para o desenvolvimento de políticas públicas e integralidade na execução dos serviços que abrangem as mulheres.

\section{Método}

O presente artigo é uma pesquisa quantitativa e documental realizada a partir do levantamento de produções científicas publicadas nos períodos de 2013 a 2015, localizadas nas bases de dados Pepsic e Portal Scielo, pelo método de revisão sistemática de seus resumos.

Conforme Sampaio e Mancine (2006), a revisão sistemática é uma forma de pesquisa que utiliza como fonte de dados a literatura sobre determinado tema e que disponibiliza um resumo das evidências relacionadas a uma estratégia de intervenção específica, mediante a aplicação de métodos definidos e sistematizados de busca, apreciação crítica e síntese da informação selecionada. Sua utilidade consiste em integrar informações de diversos estudos realizados separadamente para apresentar resultados que podem conflitar ou coincidir, além de identificar temas que necessitam de evidência e auxiliar na orientação de investigações futuras, cabendo apropriadamente no objetivo desta pesquisa aqui proposta.

Em relação aos descritores utilizados, cabe realizar um adendo sobre a escolha das palavras-chave na elaboração deste artigo. De acordo com Pedro (2005), a categoria analítica "mulher" é proveniente da segunda onda do feminismo, quando mulheres constatam a categoria "homem" como universal, fato que excluía questões referentes ao universo feminino como a violência doméstica. Contudo, com a terceira onda do movimento, em meados dos

\section{POLÊM!CA $\mid$ LABORE}


anos 1990, mulheres refletem que as opressões são distintas entre as diferentes mulheres e suas realidades, portanto, com o fim de dar estatuto à diferença dentro da diferença, surgiu a categoria "mulheres".

Já a categoria gênero, segundo Pedro (2005), emergiu no interior dos debates que se travavam dentro do movimento feminista. Segundo a autora, foi entre aquelas que escreviam as histórias das mulheres que a categoria análise de gênero passou a ser utilizada. Cabe apenas pontuar a historiadora Joan Scott (1990), autora de um importante artigo intitulado "Gênero: uma categoria útil de análise" que, além de criticar a produção feminista de ahistórica, irá considerar gênero como um constructo de relações sociais baseadas nas diferenças dos sexos e constituídas em relações de poder. Para a teórica, gênero é uma organização social da diferença sexual como também é um saber que estabelece significado para as diferenças corporais.

Esta pesquisa optou por utilizar a categoria "mulheres" em seu título por reconhecer que, embora a opressão feminina seja uma realidade constante nas diferentes realidades socioculturais, existem diferentes opressões vivenciadas por elas. Todavia, visando não excluir pesquisas que abordaram a categoria "mulher", utilizou-se como estratégia para obtenção das publicações os seguintes descritores: violência contra a mulher, violência contra as mulheres e violência de gênero.

Para a coleta de dados foram adotados os seguintes critérios de inclusão: pesquisas na língua portuguesa, artigos disponíveis online e com acesso gratuito da publicação na íntegra, publicados nos últimos três anos, nas bases de dados Pepsic e Scielo. Foram excluídos: artigos em língua estrangeira, artigos repetidos, artigos fora da data estipulada, guias médicos, resenhas, comentários, relatórios técnicos e científicos, dissertações, artigos em língua portuguesa publicados no exterior e documentos governamentais. Em momento posterior, excluíram-se artigos relacionados à violência contra o idoso, crianças, adolescentes, transexuais, travestis, intersexos, violência obstétrica no âmbito institucional, artigos associados aos agressores ou aqueles em que o tema central, isto é, seu objeto de estudo não eram as mulheres enquanto vítimas.

O mapeamento dos resumos do conjunto de produções científicas foi realizado a partir das seguintes variáveis:

\section{POLÊM!CA $\mid$ LABORE}


- $\quad$ Área de conhecimento da revista ou de atuação profissional: verificou-se pelo título da revista, autores e palavras-chaves ao longo do resumo.

- Abordagem de estudo: Foram considerados estudos quantitativos, aqueles que apresentavam indicadores estatísticos com descrições matemáticas; quanti-qualitativos quando descritos pelos próprios autores e qualitativos quando se referiam a relações, atividades humanas e que apresentavam como metodologia a análise de entrevistas e estudos teóricos bibliográficos.

- $\quad$ Tipologia de violência: A partir da leitura dos resumos, optou-se por utilizar os tipos violência doméstica - quando se referia aos três tipos de violência (física, moral, psicológica) e de acordo com que foi citado no próprio resumo; sem definição - quando se argumentava apenas a palavra violência sem especificar; violência física - quando este era o enfoque; violência sexual e institucional - quando se referia à análise da Lei Maria da Penha.

- Sujeitos da Pesquisa: mulheres, profissionais de saúde e profissionais do âmbito jurídico.

- $\quad$ Ano de publicação: Período de 2013 a 2015.

- $\quad$ Número de autores: Referenciado conforme a quantidade de autores dos manuscritos.

- $\quad$ Sexo dos autores: Verificou-se se os pesquisadores sobre a temática são homens ou mulheres.

- Conclusão: Identificou-se na conclusão dos resumos como é evidenciado o sofrimento das mulheres.

Os dados foram coletados diretamente dos sites referenciados, organizados em ficha documental, com base nas variáveis já descritas, tabulados e quantificados. A busca dos artigos e análise dos resultados ocorreu em junho de 2016.

\section{Resultados}

Os resultados serão mostrados de forma descritiva, utilizando gráficos e tabelas para melhor visualização dos dados, que serão organizados de acordo com a metodologia proposta. Portanto, inicialmente serão apresentados: 1) Resultado da pesquisa por indicadores, 2) Resultado da pesquisa após análise dos critérios de exclusão; 3) Área de conhecimento ou atuação do Profissional; 4) Pesquisadores: número de autores e sexo; 4) Metodologia:

\section{POLÊM!CA $\mid$ LABORE}


Tipologia de violência, sujeitos da pesquisa, abordagem de estudo, ano de publicação, 5) Conclusão.

$\underline{\text { Resultado da pesquisa por indicadores }}$

Scielo

Figura - 1: Gráfico- Resultados dos Indicadores da Pesquisa

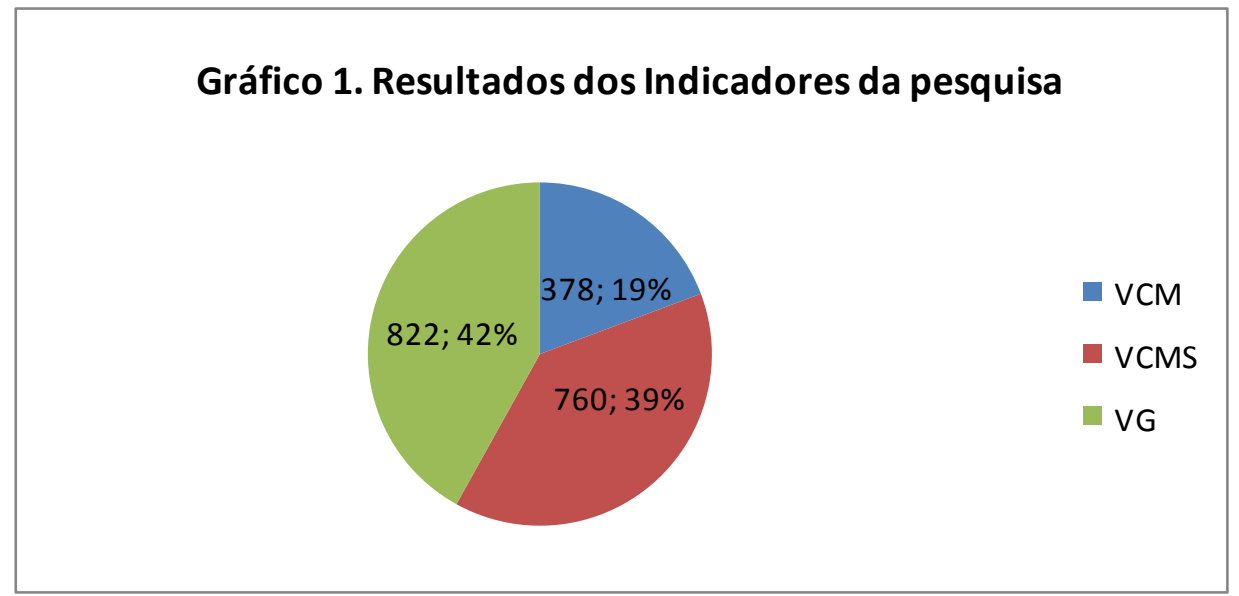

Ao procurar pelos indicadores nas bases de dados produtos, destes, 760 são referentes ao descritor "Violência, mulheres" (VCMS); 378 textos relacionados à "violência, mulher" (VCM) e 822 resultados referentes às palavras "violência, gênero" (VG). Contudo, considerando o primeiro critério de inclusão, nos últimos três anos (2013, 2014 e 2015), houve uma redução considerável: 250, 103 e 280, respectivamente, e conforme pode ser observado na tabela e no gráfico abaixo:

Tabela - 1: Dados brutos dos indicadores

\begin{tabular}{|l|l|l|l|l|l|}
\hline \multirow{2}{*}{\multicolumn{1}{c|}{ Descritores }} & \multicolumn{2}{c|}{ Ano } & \multicolumn{2}{c|}{ Dados finais } \\
\cline { 2 - 6 } & $\mathbf{2 0 1 3}$ & $\mathbf{2 0 1 4}$ & $\mathbf{2 0 1 5}$ & Total & \% \\
\hline Violência; Mulheres & 73 & 78 & 99 & 250 & $32,89 \%$ \\
\hline Violência; Mulher & 20 & 41 & 42 & 103 & $27,25 \%$ \\
\hline Violência; Gênero & 84 & 114 & 82 & 280 & $34,06 \%$ \\
\hline
\end{tabular}

\section{POLÊM!CA $\mid$ LABORE}


Figura - 2: Tabela de descritores nos últimos três anos

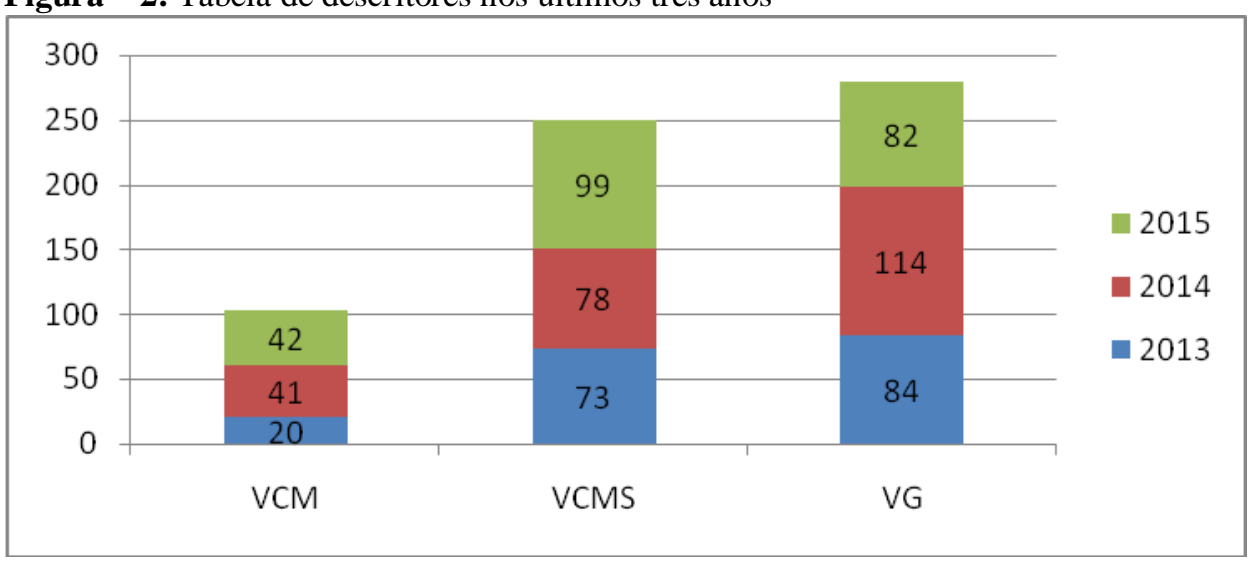

Pode-se considerar que de 760 artigos referentes à "Violência e mulheres", 32,89\% foram realizados nos últimos três anos. Dos 378 textos relacionados aos descritores "Violência, Mulher", 27,25\% foram publicados no triênio investigado e, por fim, dos 822 produtos alcançados pelas palavras-chaves "Violência, Gênero", encontrou-se 34,06\% publicações.

Em 2013, foram encontradas 177 publicações. No ano de 2014 houve um aumento para 233 manuscritos e no ano de 2015 este número foi de 223 - dado proporcional ao ano anterior, se considerarmos que alguns materiais ainda podem estar no prelo.

Pepsic

Em relação à base de dados Pepsic, foram encontrados 24 manuscritos. Destes, 4 nos descritores Violência contra as mulheres (VCMS); 8 relacionados à Violência de Gênero (VG) e 12 em relação ao termo "Violência contra a mulher" (VCM). Em relação aos últimos três anos, verificou-se que apareceram resultados em relação à VG - 4 publicações - e em relação à VCM - 8 manuscritos.

$\underline{\text { Resultado da pesquisa após análise de critério de exclusão }}$

Após eliminar artigos que se referiam a violência contra idosos, crianças, presidiárias, transexuais, travestis, intersexos, agressores, violência institucional, obstétrica, bem como os artigos que repetiam pelos seus descritores em comum e aqueles cujas pesquisas não foram realizadas no Brasil e que não foram publicados na Língua Portuguesa, verificou-se o quantitativo de 59 artigos. Em relação à base de dados Pepsic, restaram apenas 6 textos, todos

\section{POLÊM!CA $\mid$ LABORE}


nos descritores violência contra a mulher (VCM). Portanto, serão analisados dados de 65 publicações.

Figura - 4: Fluxograma de seleção dos artigos. Belém, Pará, 2016.

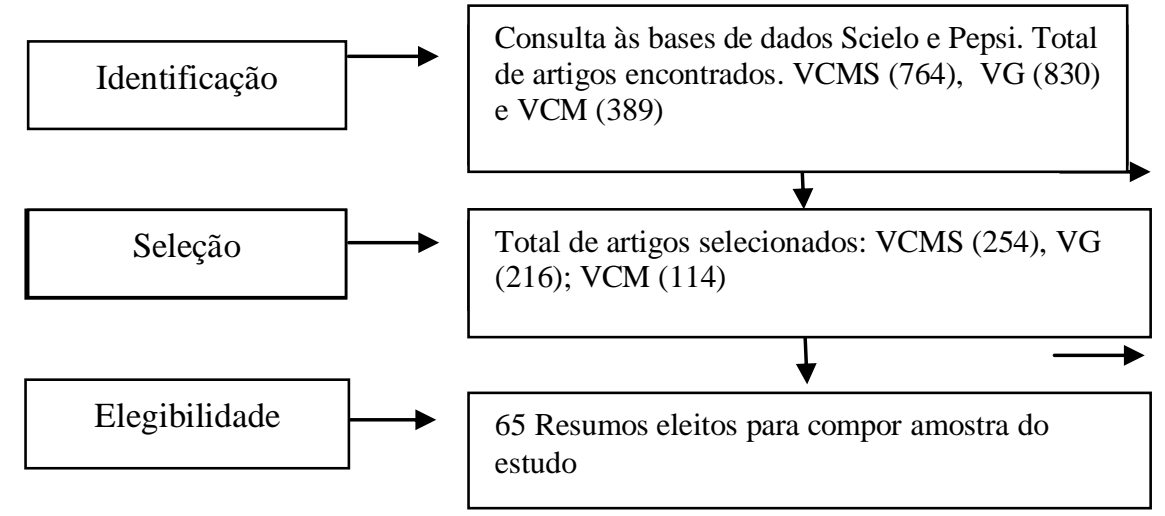

Seleção de artigos nos últimos três anos; leitura de títulos

$\underline{\text { Área de conhecimento ou atuação do Profissional }}$

Figura - 5: Área do conhecimento ou atuação profissional

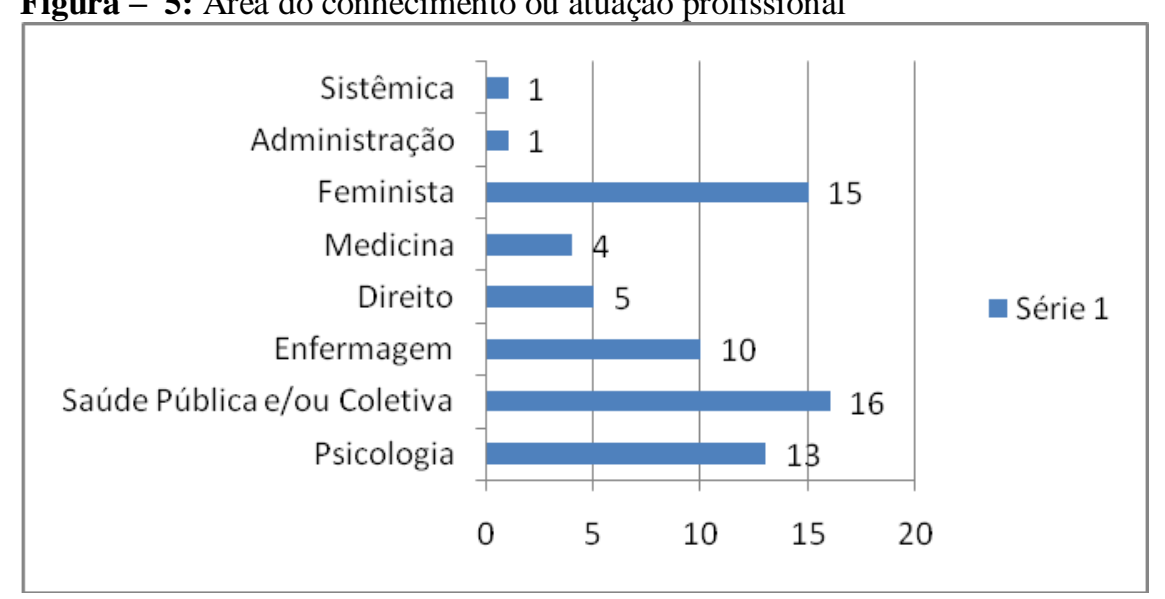

Dos 65 resumos analisados, verificou-se que 16 publicações ocorreram em Saúde coletiva, 15 em revistas feministas, 13 em revistas de psicologia ou artigos de psicologia em outras revistas, inclusive feministas, 10 em enfermagem, 5 em direito, um artigo em uma revista de administração e 1 em teoria sistêmica.

Pesquisadores: número de autores e sexo dos autores

Em relação aos autores, verificou-se que a maior parte dos estudos foram publicados por 2 a 3 autores (32 publicações, contabilizando 49,23\%), seguidos de publicações realizadas

\section{POLÊM!CA $\mid$ LABORE}


por 1 autor (25 manuscritos correspondentes a 38,46\%) e somente 8 por 4 ou mais autores $(12,3 \%)$

Quanto ao sexo, a grande maioria das pesquisas foi realizada exclusivamente por mulheres, com 54 artigos (83\%), 8 foram produzidos por mulheres em parceria com homens $(12,3 \%)$ e 3 elaborados por pessoas do sexo masculino $(4,7 \%)$.

Metodologia: Tipologia de violência; sujeitos da pesquisa; abordagem de estudo

$\mathrm{Na}$ maior parte da pesquisa, observa-se que os objetos de estudo foram as vítimas (26) e os profissionais de saúde (11). Ademais, 7 eram teóricos, 5 foram construídos a partir de artigos científicos, 4 focaram na análise das instituições, 4 na análise da Lei, 2 em conjunto com profissionais de saúde, 2 propondo-se analisar agentes jurídicos ou de segurança e 4 propunham-se a repensar em estratégias alternativas e/ou lúdicas para propiciar escuta das mulheres.

Em relação à abordagem de estudo, 52 pesquisas apresentaram enfoque qualitativo, 8 quantitativas e 5 quanti-qualitativa. As principais formas de violência identificadas foram: citando violência doméstica (35 artigos), citando violência física, sexual e psicológica (7 artigos), física e psicológica (5 artigos), sexual (4 artigos), física (1 artigo) e envolvendo a associação entre raça, gênero e violência (1 artigo).

$\mathrm{Na}$ maioria dos artigos a violência física pareceu representar violência de gênero e violência doméstica, aparecendo isolada ou associada a outra violência. Entretanto, alguns resumos não especificaram a tipologia da violência (12 artigos).

\section{Conclusão}

A maioria dos artigos - 20 publicações - evidenciou a fragilidade dos serviços de saúde (20), 15 referem sofrimento psíquico das mulheres associados à violência, outros irão concluir afirmações diversas, embora próximas: a necessidade de mais estudos na área de enfermagem; a incompreensão da equipe em relação às demandas e a importância de seu serviço; o perfil de mulheres em relacionamentos estáveis, por parceiros que costumam fazer uso do álcool; a iniquidade e desigualdade, bem como questões culturais afetando na questão da violência, além da importância e aspectos positivos realizados em trabalhos de grupos

\section{POLÊM!CA $\mid$ LABORE}


terapêuticos e/ou nas unidades básicas, em especial nos programas de Estratégia Saúde da família.

\section{Discussão}

No Scielo, o maior número de pesquisas ocorreu dentro dos descritores "violência de gênero", seguido de "violência, mulheres" e "violência, mulher", respectivamente. No PEPSIC, após estabelecidos os critérios de exclusão, o número de publicações recentes concentrou-se nos indicadores "violência, mulher". Contudo, a última base de dados apresentou um número reduzido de artigos quando comparada à primeira base de dados.

Na pesquisa de Silva e Oliveira (2013), as publicações no período de 2009 a 2013 apresentaram uma média de 30 artigos. Em relação a esta pesquisa, verificou-se que em 2013 a média de publicações foi de 59 artigos, em 2014 de 77 e em 2015 de 74 manuscritos, demonstrando um aumento de publicações.

Autores como Santos e Izumo (2005) afirmam que a própria literatura sobre violência contra a(s) mulher(es) recebe influências sócio-históricas, uma vez que acompanha não apenas as mudanças legais, como a criação de delegacias para o público feminino e a Lei Maria da Penha, mas também os estudos que analisam e refletem sobre subjetividade e relações de gênero.

Em sua pesquisa, estas autoras destacam três correntes teóricas de análise em relação à violência contra as mulheres: uma nomeada "dominação masculina", em que os autores consideram que a violência é resultante da dominação masculina e corresponde à anulação da autonomia da mulher, vítima e cúmplice, tendo como principal representante deste conceito de violência a filósofa Marilene Chauí; a segunda, intitulada de "dominação patriarcal", representada pelos estudos de Saffiotti, é influenciada pelo feminismo e marxismo, considera a mulher um sujeito autônomo, porém historicamente vítima do patriarcado, sendo a violência uma expressão deste; e a corrente "relacional", cuja influência advém do feminismo dos anos 1990 com Joan Scott e que relativizará o binômio dominação masculina versus vitimização feminina ao entender violência como uma maneira de comunicação (SANTOS \& IZUMO, 2015, p.2).

As autoras, que em 2005 se propuseram realizar uma pesquisa sobre as referências teóricas das Ciências Sociais na área da violência, analisando os conceitos de violência contra

\section{POLÊM!CA $\mid$ LABORE}


as mulheres e violência de gênero nos últimos 25 anos, afirmaram, como resultado, que as pesquisas não precisam das diferenças conceituais entre expressões como "violência contra as mulheres", "violência de gênero", "violência conjugal", "violência familiar" e "violência doméstica". Este dado fora confirmado, uma vez que na leitura de resumos verificou-se a utilização de inúmeros termos, tais como: violência por parceiros íntimos, violência íntima, violência doméstica, violências privadas, violência de gênero, violência física ou somente violência.

Verificou-se que nos resumos analisados os relatos das vítimas foram identificados por meio de entrevistas, isto é, de forma direta, ou na leitura de fichas de identificação, laudos periciais, prontuários e boletins de ocorrência. Apesar da preocupação maior centrar na escuta das vítimas, como já apontado no estudo de Silva e Oliveira (2013), verificou-se um aumento das pesquisas realizadas com profissionais de saúde e, em especial, publicações na área da saúde (16), analisando os serviços do SUS e a importância da tecnologia do cuidado como ferramenta. Além de abordar a área de enfermagem e medicina, foram encontrados artigos sobre agentes comunitários (2), Estratégia Saúde da Família (3) e NASF (1).

Contudo, corroborando com a pesquisa já citada, ressalta-se a importância da escuta das vítimas, pois é a partir da realidade e experiências que se pode pensar nas ações e políticas de saúde. Evidencia-se que os artigos denunciam a fragilidade na execução da lei, bem como as dificuldades de profissionais que carecem de compreensão acerca do seu fazer, que descumprem a Lei Maria da Penha, bem como denunciam a carência de contratação de profissionais especialistas que auxiliem na melhor oferta de acolhimento às vítimas.

É importante frisar que a maior parte dos estudos encontrados é qualitativa (80\%), confirmando tal enfoque como uma tendência de estudo para avaliar VCMS proposto por Pereira et al (2010) que em sua pesquisa sistemática, realizada no período de 2005 e 2009, encontrou 49\% dos trabalhos nesta perspectiva, assim como Silva e Oliveira (2013) que evidenciaram $54,7 \%$ de pesquisas qualitativas.

Verificou-se que a maioria dos artigos abordou a violência doméstica, em especial, a violência física. Somente 5 especificaram a violência doméstica como violência física, psíquica e sexual e nenhum referiu-se à violência patrimonial, o que pode ser um indicativo de sua invisibilidade nos estudos, abordagens e aplicação da lei, sendo, portanto, um objeto

\section{POLÊM!CA $\mid$ LABORE}


para futuras pesquisas. Também se encontrou apenas 2 publicações abordando sobre feminicídio e 5 sobre violência sexual.

Um fato que merece destaque é de que os homens não têm publicado em relação a esta temática (foram encontradas apenas 3 publicações de artigos elaborados por pessoas do sexo masculino), demonstrando um indicador que merece análise e futuras pesquisas, uma vez que apenas as mulheres têm se debruçado sobre este crime que revela uma violência de gênero.

Foram identificadas outras lacunas em relação aos resumos analisados, que estão em consonância com as pesquisas anteriores já citadas neste artigo (PEREIRA et al, 2010; SILVA \& OLIVEIRA, 2013): a escassez de pesquisas em relacionamentos homossexuais; artigos sobre a cultura do estupro; sobre a VCMS veiculada nas mídias, com pessoas com deficiência e indígenas, VCMS na perspectiva do agressor, VCMS nas escolas, trabalho, igreja, tal como já observado por Oliveira e Silva (2013).

Estas autoras sugerem necessidade de estudo com públicos de outras rendas que não apenas de nível socioeconômico desfavorecido, além de apontar a necessidade de realizar pesquisa para além dos hospitais e unidades de saúde, pois embora muitos procurem assistência em função das lesões, o que pode levar a uma superestimação da violência, há também muitos que não procuram órgãos que possam atestar a violência por questões psíquicas e/ou por medo, para proteger o companheiro, por vergonha, etc.

Outro fator que merece destaque foi a baixa produção em relação à raça, classe econômica e faixa etária, uma vez que tais aspectos merecem ser destacados e analisados, pois quando negados podem cair na invisibilidade, propiciando violência simbólica ao ocultar realidades presentes no Brasil, como o racismo estrutural que afeta diretamente as mulheres negras.

\section{Conclusão}

Este trabalho foi um estudo sistemático e documental, com o objetivo de mapear a temática produzida sobre VCMS. Com o objetivo de compilar informações importantes, teve como principal proposta facilitar o acesso de profissionais e pesquisadores sobre $\mathrm{o}$ conhecimento produzido nos últimos três anos, dando continuidade a outras pesquisas já realizadas.

\section{POLÊM!CA $\mid$ LABORE}


Contudo, é preciso evidenciar que este estudo não abrange toda produção nacional sobre o tema, uma vez que muitos pesquisadores publicam em revistas internacionais e que há outras bases de dados a serem investigadas. Portanto, propõe-se a continuidade desta pesquisa com a leitura minuciosa dos artigos aqui analisados somente por seus resumos. Sugere-se também novos estudos utilizando outras variáveis, inclusive sobre os pesquisadores que escrevem sobre a temática.

É ressaltado o compromisso político em evidenciar dados sobre as pesquisas, uma vez que além de vislumbrar contribuir com a atuação profissional e conhecimento científico, visase colaborar também com gestores em políticas públicas para promoção de saúde das mulheres e ações que possam dar visibilidade à problemática e tenham efeitos nas distintas realidades de violência vivenciadas por tantas mulheres.

\section{Referências}

AMARANTINO, M.; DEL PRIORI, M. (Org.). História do corpo no Brasil. São Paulo: Editora Unesp, 2011.

BRASIL. Presidência da república. Lei 11.340, de 7 de agosto de 2006. Cria mecanismos para coibir a violência doméstica, nos termos $8^{\circ}$ do artigo 226 da Constituição Federal, da Convenção da Eliminação de todas as formas de discriminação contra as mulheres e da Convenção Interamericana para Prevenir, Punir e Erradicara Violência contra a mulher; dispõe sobre a criação do juizado de violência doméstica e familiar contra a mulher; altera o Código Penal e a Lei de Execução Penal, e dá outras providências. Diário oficial da União. Brasília, DF, 2006, 8 agos.

BRASIL. Presidência da república, Lei n 2.848, prescreve o feminicídio como circunstância qualificadora do crime de homicídio e o art. $1^{\circ}$ da Lei n 8.072, de 24 de julho de 1990, para incluir o feminicídio no rol dos crimes hediondos. Diário oficial da União, Brasília, DF, 2015, 9 março.

COELHO, L. N. Freud: Violência e cultura. Dissertação de Mestrado em Psicologia Clínica e Social. Belém: Universidade Federal do Pará, 2015. Disponível em: www. Ppgp.com.br.

CUNHA, B. Violência contra a mulher, direito e patriarcado: perspectivas de combate à violência de gênero. Artigo publicado na XVI Jornada de Iniciação Científica de Direito. UFPR, 2014. Disponível em:

http://www.direito.ufpr.br/portal/wp-content/uploads/2014/12/Artigo-B\%C3\%A1rbara-Cunha-classificado-em7\% $2 \%$ BA-lugar.pdf.

DINIZ, N. M. F. et al. Aborto provocado e violência doméstica entre mulheres atendidas em uma maternidade pública em Salvador - BA. Revista brasileira de enfermagem, v. 64, n. 6, pp. 1010-1015, 2011.

PEDRO, J. M. Traduzindo o debate: o uso da categoria gênero na pesquisa histórica. História, v. 24, n. 1, pp. 77-98, 2005.

PEREIRA, A. S. et al. Produção científica sobre violência contra a mulher no período de 2005-2009. Cadernos da escola de saúde pública, v. 4, n. 2, pp. 42-47, 2010.

SAMPAIO, R. F; MANCINE, M. C. Estudos de revisão sistemática: um guia para síntese criteriosa de evidência científica. Rev Brás de fisioterapia, v. 11, n. 1, pp. 83-89, 2007.

\section{POLÊM!CA $\mid$ LABORE}

Polêmica - Revista Eletrônica da Uerj - Rua São Francisco Xavier, 524, $1^{\circ}$ andar

bloco D, sl.1001 • Tels.: +55 21 2334-4088/4087 • http://www.e-publicacoes.uerj.br/index.php/polemica/index http://www.labore.uerj.br • laboreuerj@yahoo.com.br 
SANTOS, C.; IZUMINO, W. Violência contra as mulheres e Violência de gênero: Notas sobre Estudos Feministas no Brasil. Estudios Interdisciplinarios de América Latina y El Caribe, 2005.

SCOTT, J. Gênero: uma categoria útil para análise histórica. Tradução: Tradução: Christine Rufino Dabat e Maria Betânia Ávila, 1990. Disponível em:

http://www.dhnet.org.br/direitos/textos/generodh/gen_categoria.html.Acessado em: 03/07/2016.

SILVA, L.; OLIVEIRA, M. Violência contra a mulher: revisão sistemática da produção científica nacional no período de 2009 a 2013.Ciência \& Saúde Coletiva, v. 20, n. 11, pp. 3523-3532, 2015.

SILVA, A.C. et al. Violência contra mulher: uma realidade imprópria. Ciênc. Saúde Nova Esperança, v. 11, n. 2, pp. 101-15, 2013.

WAISELFISZ, J. Mapa da violência 2015: Homicídio das mulheres no Brasil. São Paulo. Instituto Sangari. 2015.

Recebido em: 24/05/2017.

Aceito em: 20/08/2017.

\section{POLÊM!CA $\mid$ LABORE}

